\title{
Rapid palpitations: three of a kind?
}

\author{
R. Evertz • E. Arbelo • L. Mont
}

Published online: 24 July 2013

(C) The Author(s) 2013. This article is published with open access at Springerlink.com

A 33-year-old male with symptoms of rapid palpitations with sudden onset was seen in our institution. The patient did not have any medical history and was not on medical treatment. Baseline electrocardiogram was completely normal. Structural heart disease was excluded and the family history was negative for sudden cardiac death. The patient was referred for electrophysiological study. During the procedure the following tachycardia was induced
(Fig. 1). A tachycardia with a heart rate of approximately 200 beats per minute (bpm) with different QRS morphologies can be appreciated. The patient recognised the symptoms. What do we see? What happened and does this give us a clue to the diagnosis?

\section{Answer}

You will find the answer elsewhere in this issue.

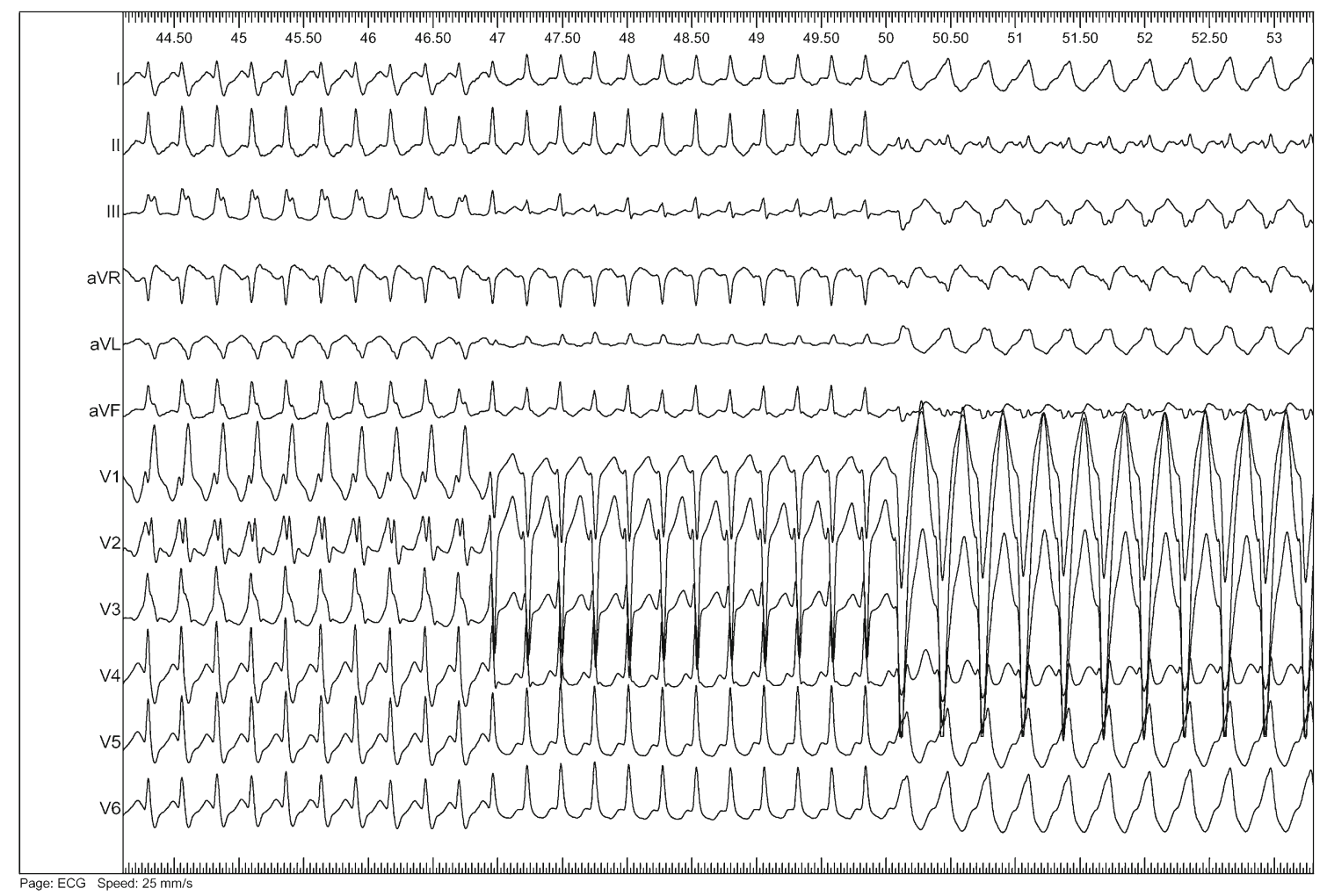

Fig. 1 Twelve-lead electrocardiogram (ECG) of the induced tachycardia

R. Evertz $(\bowtie) \cdot$ E. Arbelo $\cdot$ L. Mont

Cardiology Department - Arrhythmia Section,

Thorax Institute - Hospital Clínic, University of Barcelona,

Villarroel 170, 08036 Barcelona, Spain

e-mail: reinderevertz@gmail.com
Open Access This article is distributed under the terms of the Creative Commons Attribution License which permits any use, distribution, and reproduction in any medium, provided the original author(s) and the source are credited. 